\title{
Influence of Components of Internal Control on the Effectiveness of Internal Control: Evidence from Transport Construction Enterprises in Vietnam*
}

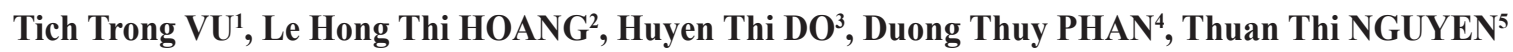

Received: August 01, 2020 Revised: October 05, 2020 Accepted: October 15, 2020

\begin{abstract}
The research purpose of the article is to evaluate the effects of the internal control components on the effectiveness of internal control of transport construction enterprises in Vietnam, on the basis of which we made recommendations to contribute to improving the effectiveness of internal control. Sample was collected from Vietnamese medium and large transport construction enterprises, the total number of sample questionnaires sent was 400, 330 filled-up questionnaires was collected and 250 was used for the study purpose. Quantitative research method was used for the study with the help of the SPSS software. The variables in the model are as follows: the dependent variable is the effectiveness of internal control, 5 independent variables are: control environment, risk assessment, control activities, communication, and monitoring. The results of the analysis explain $80.4 \%$ variation as a result of the effect of internal control on the Vietnamese transport construction enterprise. All five components positively affect the effectiveness of internal controls in the order of influence, which are: control activities, control environment, communication, risk assessment and monitoring. This study contributes in providing more empirical evidence about the effects of internal control components on the effectiveness of internal control of transport construction enterprises in Vietnam. The study has proposed a number of recommendations to help transport construction enterprises improve control activities and contribute towards improving the effectiveness of internal control.
\end{abstract}

Keywords: Components of Internal Control, Internal Control, Transport Construction Enterprises

JEL Classification Code: G30, M40, M41

\begin{abstract}
*Acknowledgements:
The authors are thankful to University of Transport and Communications and University of Transport Technology for funding this research. We would like to thank the anonymous referees for their helpful comments and suggestions.

${ }^{1}$ First Author. Dean, Faculty of Transport Economics, University of Transport and Communications, Vietnam. Email: vttich@utc.edu.vn ${ }^{2}$ Dean, Faculty of Transport Economics, University of Transport Technology, Vietnam. Email: lehth@utt.edu.vn

${ }^{3}$ Lecturer, Faculty of Transport Economics, University of Transport Technology, Vietnam. Email: huyendt@utt.edu.vn

${ }^{4}$ Corresponding Author. Lecturer, Faculty of Transport Economics, University of Transport Technology, Vietnam [Postal Address: 54

Trieu Khuc Road, Thanh Xuan District, Hanoi, 120418, Vietnam] Email: duongpt@utt.edu.vn

${ }^{5}$ Lecturer, Faculty of Transport Economics, University of Transport Technology, Vietnam. Email: thuannt@utt.edu.vn

(c) Copyright: The Author(s)

This is an Open Access article distributed under the terms of the Creative Commons Attribution Non-Commercial License (https://creativecommons.org/licenses/by-nc/4.0/) which permits unrestricted non-commercial use, distribution, and reproduction in any medium, provided the original work is properly cited.
\end{abstract}

\section{Introduction}

The topic of internal control and effectiveness of internal control has received attention from researchers, there have been many studies on this issue being done domestically as well as abroad. Generally, internal control is a process consisting of activities, processes, policies and control points designed and applied by an enterprise; Internal control consists of 5 components: control environment, risk assessment, control activities, communication and monitoring. In order for internal control to operate smoothly and to achieve business goals, including performance, reporting and compliance objectives, the full presence and coherence of five components mentioned above is required.

While researching related to internal control components and internal control effectiveness, the authors found that: in the world there are many studies on the influence of control components. Effect of internal control has been studied in 
many fields such as in banking, education, health, public sector, however, there have not been many studies on this issue in the field of transport construction enterprises. In the country, there have been no studies on the effects of internal control components on the effectiveness of internal control of transport construction enterprises.

In Vietnam, construction of transport works is an industry that creates technical infrastructure and plays an important role in the national economy. The volatility of the business environment and the inevitable contradictions arising in the growth process require Vietnamese businesses to increasingly focus on risk management (Dang et al, 2020). According to a summary by researchers, the transport construction industry contributes an average of $15-16 \%$ of GDP, of which, the transport construction enterprises contribute a large part. In recent years, many transport construction enterprises have fallen into a difficult situation, revealing many weaknesses. Regarding the results of production and business activities, according to the General Statistics Office, revenue from transport construction activities of transport construction enterprises in 2018 decreased by $38.2 \%$ over the previous year. In 2017, profit after tax in 2018 decreased by $54.1 \%$ compared to 2017. In the three consecutive years, from 2016 to 2018 , about $30 \%$ of transport construction enterprises suffered losses. This shows signs of going down in production and business activities of transport construction enterprises. It can be seen that part of the above subjective reasons is related to the internal control of the business. According to Hardiningsih (2020) through internal control in the village government, it is evident that the use of village funds can be managed properly so that accountability in the management of VFA is in accordance with applicable laws and regulations. Firms need to be transparent and disclose their business results in accordance with current regulations and with the approach of international standards (IFRS) (Nguyen et.al, 2020).

The study aims to evaluate the effects of internal control components on the effectiveness of internal control of Vietnamese transport construction enterprises. The results of the study provide more evidence about the influence of internal control components on the effectiveness of internal control of the Vietnamese transport construction enterprises, from which recommendations can be made towards the great effect of internal control of these businesses.

\section{Literature Review}

\subsection{The Theory Foundation}

\section{Agency theory}

Agency Theory developed by Jensen and Meckling in 1976 published a study on the relationship between the authorized and authorized parties. The theory stems from the separation of ownership and control rights, this theory becomes more and more popular when businesses grows, expand in size, owners cannot participate in operating. businesses, instead they tend to hire executives. Delegation theory helps to explain the existence of internal control as a mechanism for monitoring the manager's behavior to ensure that the attorney will represent the principal's interests, minimizing disadvantages for enterprise.

\section{Chaos theory}

Chaos theory is an area of study in Mathematics and applied to other sciences such as Economics, Philosophy, and Biology. Chaos theory also shows the factors in control. There is always an internal relationship and a close correlation with each other, even a very small mistake of one factor also affects other factors and is detrimental in achieving the goals of the business.

\section{Contingency theory}

Contingency theory was initiated in 1980 by Otley and developed in 2009 by Otley and Ferreira. This theory holds the view that no single effective governance system is suitable for all organizations and suitable for all situations because the unique characteristics of the system and its effectiveness depends on the specifics of the organization and the actors in the context. Contingency theory is widely used in the field of accounting, as the foundation to explain the relationship between accounting performance with employee qualifications, and independent audit. According to Luft and Shields (2003), Contingency theory is an important theory to explain the complex relationship between changes in the management accounting system and internal and external factors within an organization.

\section{Psychological and social theory}

This theory states that "the effectiveness of governance is determined by labor productivity, but labor productivity is determined not only by physical factors but also by satisfaction and psychosocial needs of people (Hellriedel et al., 1986). Mayo (2004) said that the satisfaction of human psychological needs such as wanting to be cared for, respected by others, wanting to have an important role in a common career, and wanting to work in a friendly atmosphere among colleagues, has a great influence on the productivity and results of human labor. Social psychology theory in the organization helps explain the existence of control, monitoring and communication activities that help businesses achieve their goals.

\section{Stakeholder theory}

The theory of stakeholders first initiated by Freeman in his book "management strategy", is a theory of the management 
and business ethics of an organization. Applying the theory of parties with related interests and obligations helps enterprises determine the appropriate parties with related interests and obligations, determine the limits and scope under the control of the enterprise, to reduce risks, reduce impact and bad impact on the organization, ensuring that the business can achieve its set goals.

\subsection{Literature Review}

Amudo and Inanga (2009) studied the impact of environmental factors such as: control, risk assessment, control activities, information and communication, monitoring, and information technology to Internal control effect of Ugandan public sector projects financed by the African Development Bank during the period 20032007. The dependent variable is the effect of internal control; Independent variables are components of internal control under COSO and supplement with COBIT based information technology components, including: control environment, risk assessment, control activities, information and communication, monitoring, information technology. Research results show that: some components of the internal control system of these projects are defective, leading to the ineffective operation of internal control.

Sultana and Haque (2011) studied the effects of the internal control components on the internal control effectiveness of the 6 listed private banks in Bangladesh. Dependent variables were: internal control effect, independent variable, control environment, risk assessment, information and communication, control activities and monitoring. Moderator variables were: authorization and partnership relationship. Research results show that the components in internal control work well and will provide reasonable assurance of control objectives, and will ensure the effectiveness of internal control.

Gamage et al. (2014) studied the effects of components of internal control on the effectiveness of internal control of two state-owned commercial banks and 64 branches of banks in Sri Lanka. Dependent variable in the study was the internal control effect; independent variables were: control environment, risk assessment, information and communication, control activities, and monitoring. Research results show that there is a positive impact of the components of internal control on the effectiveness of internal control.

Ayagre et al. (2014) studied the impact of two components of internal control, namely the control environment and supervisory activities on the effectiveness of the internal control of the bank at Ghana. The study results show that there is a strong impact of the control environment and supervisory activities on the effectiveness of the bank's internal control at the Ghanaian bank.
$\mathrm{Vu}$ (2016) studies the factors affecting the effectiveness of the internal control system in Vietnamese commercial banks. The study results show the order of the influence of factors on the effectiveness of the internal control system in Vietnamese commercial banks as follows: risk assessment, control activities, information media, political institutions, surveillance, control environment, and group interests.

The above studies focus only on the economies of emerging countries, namely Ghana, Sri Lanka, and Bangladesh. In Vietnam, research on the effects of internal control components on the effectiveness of internal control is quite small, especially research on transport construction enterprises is not available. Therefore, within the research scope, the research on influencing the internal control components on the internal control effectiveness is studied to verify and identify factors affecting the effectiveness of internal control in Vietnam, thereby contributing towards the improvement of the effectiveness of internal control in the transport construction enterprises in Vietnam.

\section{Methodology}

\subsection{Hypothesis}

Improving the efficiency of internal control is one of the conditions to ensure the efficiency and sustainable development of a business within the legal framework of the state. The effectiveness of internal control is influenced by many different factors, among which the factors that constitute internal control have direct effects. When one component of internal control is defective, the performance of internal control is not highly effective (Amudo \& Inanga, 2009). Well-functioning departments of internal control will properly ensure control objectives and ensure effectiveness of internal control (Sultana \& Haque, 2011).

H1: The control environment has a positive impact on the internal control effectiveness of transport construction enterprises.

Hypothesis $\mathrm{H} 1$ is built on the basis of the internal control theory of COSO (2013) and related empirical studies. According to COSO's internal control theory, the control environment is a component of internal control, the positive 'presence' and 'operation' of the control environment component positively affects its effectiveness on. internal control. According to research by Amudo and Inanga (2009), if there is a shortage of a control environment, it reduces the effectiveness of internal control. According to Sultana and Haque (2011), a good operational control environment will reasonably ensure the realization of business performance, reporting and compliance objectives. According to Ayagre et al. (2014), the control environment has a strong impact 
on internal control effectiveness. According to Vu (2016), there is a positive impact of the control environment on the effectiveness of internal control.

H2: risk assessment has a positive impact on the effectiveness of internal control of transport construction enterprises.

Hypothesis $\mathrm{H} 2$ is built on the basis of the internal control theory of COSO (2013) and related empirical studies. According to COSO's internal control theory, the risk assessment is a component of internal control, the positive "presence" and "activity" of the risk assessment component positively affect effectiveness of internal control. Research results are in line with a number of previous studies on the positive effects of risk assessment on internal control effectiveness, Amudo and Inanga (2009), Sultana and Haque (2011), Gamage and Fernando (2014), Vu (2016).

H3: control activities have a positive impact on the effectiveness of internal control of transport construction enterprises.

Hypothesis $\mathrm{H} 3$ is built on the basis of the internal control theory of COSO (2013) and is related to empirical studies. According to COSO's internal control theory, risk assessment is a component of internal control, the presence and active "activity" of the control active component positively affects effectiveness of internal control. Some previous studies that have examined the positive effects of risk assessment on internal control effectiveness are those of the following authors, Amudo and Inanga (2009), Sultana and Haque (2011), Gamage and Fernando (2014), $\mathrm{Vu}(2016)$.

H4: Information and communication have a positive impact on the effectiveness of internal control of transport construction enterprises.

Hypothesis $\mathrm{H} 4$ is built on the basis of the internal control theory of COSO (2013) and related empirical studies. According to COSO's internal control theory, information and communication are a component of internal control, the active "presence" and "activity" of the information and communication components positively affect the effect of internal control. Several previous studies that have examined the positive effects of risk assessment on internal control effectiveness include those of the following authors, Amudo and Inanga (2009), Sultana and Haque (2011), Gamage and Fernando (2014), Vu (2016).

H5: supervision has a positive impact on the effectiveness of internal control of transport construction enterprises.
Hypothesis $\mathrm{H} 5$ is built on the basis of the internal control theory of COSO (2013) and is related to empirical studies. According to COSO's internal control theory, surveillance is a component of internal control, the active "presence" and "activity" of the information and communication component positively affect control effectiveness of internal control. Some previous studies that have examined the positive effects of surveillance on the effectiveness of internal control include studies by the authors, Amudo and Inanga (2009), Sultana and Haque (2011), Gamage and Fernando (2014), Vu (2016).

\subsection{Research Model}

To achieve the research goal, two regression equations were established as follows: A linear regression equation shows the impact of the independent variables (MT, RR, HD, TT, GS) on the variable. HL dependencies have the form:

$$
\mathrm{HL}=\beta 0+\beta 1 \mathrm{MT}+\beta 2 \mathrm{RR}+\beta 3 \mathrm{HD}+\beta 4 \mathrm{TT}+\beta 5 \mathrm{GS}
$$

In which: $\beta 0$ is constant

$\beta 1, \beta 2, \beta 3, \beta 4, \beta 5$ : regression coefficient

Conditions to make the variables meaningful in the model with $95 \%$ confidence: Sig values of the independent variables are less than 0.05 .

\subsection{Research Method}

\subsubsection{Sample Selection}

To analyze the effects of internal control components on the effectiveness of internal control of Vietnamese transport construction enterprises, research was conducted on select medium and large transport construction enterprises in Vietnam. According to the General Statistics Office, the medium and large transport construction enterprises have less than $25 \%$ of the total transport construction enterprises, but contribute about $85-90 \%$ of the total revenue and $40 \%$ of the total number of employees in the transport construction industry. It can be seen that medium and large transport construction enterprises play an important role and make a great contribution in the field of transport construction.

\subsubsection{Data Collection}

To collect data for our research, we conducted a survey. The survey questionnaire is designed to include the following information sections:

1. Information about the person to be surveyed.

2. Information on the components of internal control: including survey questions about the components of the internal control of transport construction 
firms: questions about the control environment (26 Questions), questions about risk assessment (10 questions), questions about control activities (14 questions), questions about information and communication (8 questions), and questions about monitoring (6 questions).

3. information on effectiveness of internal control: including 6 questions related to the effectiveness of internal control of the transport construction company

Part 2 and 3 based on a likert scale from 1 to 5, corresponding to five levels of agreement: strongly disagree, disagree, neutral, agree, and strongly agree.

The questionnaire form was sent to 400 of the transport construction enterprises and received 330 responses.

\subsubsection{Data Processing}

The responses were entered into Microsoft Excel, after the polling was conducted, the unsatisfactory votes were removed, and the number of votes was cleaned and put into processing was 250 votes. Data of the satisfactory cards are processed by the following methods: Cronbach's Alpha test to measure the reliability of the scale; Exploratory Factor Analysis (EFA) to divide data into smaller sets of variables to explore the basic structure; Descriptive analysis to describe the basic quantitative features of data; Correlation analysis and regression to evaluate the relationship between variables with the support of SPSS 20 software.

\section{Empirical Results}

\subsection{Reliability Analysis}

The analysis results show that in addition to the observed variable LD1 (is a variable with total variable correlation $0.187<0.3$ ), all the remaining variables have correlation coefficients of the total variables are consistent $(>0.3)$. Cronbach's Alpha values of the scales were all greater than 0.6 (mostly in the range from 0.8 to 0.95 ). With the above results, it can be shown that the scales are considered good and reliable and all observed variables (after eliminating the variable LD1) contribute to the reliability of the scale.

\subsection{Exploratory Factor Analysis (EFA)}

After assessing the reliability of the scale with Cronbach's Alpha above, the uncontrolled observational variables were continued to be included to evaluate the value of the scale.
The tool used is Exploratory Factor Analysis (EFA), which helps to evaluate two important values of the scale, the convergent value and the discriminant value. Convergence value: Observed variables of the same properties converge on the same factor, when represented in the rotation matrix, these variables will be in the same column. To ensure this factor, the team used KMO tests. Factor analysis results show that the KMO values of the scales are greater than 0.5 , satisfying the condition $0.5 \leq \mathrm{KMO} \leq 1$. Distinguishing value: The observed variables converge on this factor and must divide Unlike the variables observed in other factors, when represented in the rotation matrix, each group of variables will be separated into separate columns. To ensure this factor, the authors used the Bartlett test. The test results show that $\operatorname{sig}=0.000$, which means that the data used for factor analysis is appropriate and has statistical significance.

In addition, the total variance extracted of the scales is $>$ $50 \%$, showing that the observed variables can be explained by $>50 \%$ variation of the scale. Thus, through the EFA test, we can confirm the convergence of the scale.

After the EFA analysis, 5 scales of MT, RR, HD, TT, GS with ... observed variables were retained in the model.

$$
\mathrm{HL}=\beta 0+\beta 1 \mathrm{MT}+\beta 2 \mathrm{RR}+\beta 3 \mathrm{HD}+\beta 4 \mathrm{TT}+\beta 5 \mathrm{GS}
$$

\subsection{Correlation Analysis}

The purpose of correlation analysis is to examine the close linear relationship between the dependent variable and the independent variables.

\section{Criteria used in correlation analysis:}

Criterion 1: Pearson correlation coefficient ( $\mathrm{r}$ )

Correlation coefficient $(r)$ is a statistical index measuring the correlation relationship between two variables. The correlation coefficient $r$ has a value from -1 to 1 . When $r$ goes to -1 or 1 : the stronger the linear correlation, going to -1 is a positive correlation, going to 1 is negative. As $r$ approaches 0 , the linear correlation becomes weaker.

Criterion 2: Statistical significance $\mathrm{Sig}<0.05$

The coefficient $r$ is only meaningful when $\mathrm{Sig}<0.5$. If $\mathrm{Sig}>0.05$ then there is no correlation.

\section{Correlation analysis results}

Using IBM SPSS Statistics 20 software, the authors obtained the results of the analysis of correlation between the HL dependent variable (internal control effect) and the dependent variables MT (control environment), RR (risk assessment), HD (control activity), TT (communication), GS (monitoring) as follows (Table 2): 
Table 1: Variables Summary

\begin{tabular}{|c|c|c|c|c|}
\hline Variable & Meaning & Determined by & Model & Role \\
\hline $\mathrm{HL}$ & Effectiveness & $\begin{array}{l}\text { Mission and goals are accomplished; With an } \\
\text { available resource, work always achieves the highest } \\
\text { results; The financial statements are prepared in } \\
\text { with accounting standards and regulations; Internal } \\
\text { reports were prepared in accordance with the } \\
\text { company's form and regulations; The company } \\
\text { performed well the provisions of the law; The } \\
\text { departments / individuals have well implemented the } \\
\text { company's regulations }\end{array}$ & $\begin{array}{l}\text { HL1; HL2, HL3; HL4; } \\
\text { HL5; HL6 }\end{array}$ & $\begin{array}{l}\text { Dependent } \\
\text { variable }\end{array}$ \\
\hline \multirow{5}{*}{ MT } & \multirow{5}{*}{$\begin{array}{l}\text { Control } \\
\text { environment }\end{array}$} & General statements & $\begin{array}{l}\text { TB (includes: TB1, } \\
\text { TB2, TB3) }\end{array}$ & \multirow{5}{*}{$\begin{array}{l}\text { Independent } \\
\text { variable }\end{array}$} \\
\hline & & Ethical values & $\begin{array}{l}\text { DD (includes: DD1, } \\
\text { DD2, DD3, DD4, DD5, } \\
\text { DD6, DD7) }\end{array}$ & \\
\hline & & $\begin{array}{l}\text { Board of Directors / Board of Members and Board of } \\
\text { Directors }\end{array}$ & $\begin{array}{l}\text { LD (includes: LD1, } \\
\text { LD2, LD3, LD4) }\end{array}$ & \\
\hline & & $\begin{array}{l}\text { Organizational structure, reporting ranks, } \\
\text { assignment of responsibilities and authorities }\end{array}$ & $\begin{array}{l}\text { CC (includes: CC1, } \\
\text { CC2, CC3, CC4, CC5, } \\
\text { CC6) }\end{array}$ & \\
\hline & & Commitment to human resources & $\begin{array}{l}\text { NL (includes: NL1, NL2, } \\
\text { NL3, NL4, NL5, NL6) }\end{array}$ & \\
\hline \multirow[b]{2}{*}{ RR } & \multirow{2}{*}{$\begin{array}{l}\text { Risk } \\
\text { assessment }\end{array}$} & Determine the target & $\begin{array}{l}\text { XD (includes: XD1, } \\
\text { XD2, XD3) }\end{array}$ & \multirow{2}{*}{$\begin{array}{l}\text { Independent } \\
\text { variable }\end{array}$} \\
\hline & & Risk identification, risk assessment & $\begin{array}{l}\text { DG (includes: DG1, } \\
\text { DG2, DG3, DG4, DG5, } \\
\text { DG6, DG7) }\end{array}$ & \\
\hline \multirow{2}{*}{ HD } & \multirow{2}{*}{ Control actives } & $\begin{array}{l}\text { Ensuring the principles of Assignment, Non-part- } \\
\text { time, Authorization for approval }\end{array}$ & $\begin{array}{l}\text { NT (includes: NT1, } \\
\text { NT2, NT3, NT4, NT5, } \\
\text { NT6, NT7) }\end{array}$ & \multirow{2}{*}{$\begin{array}{l}\text { Independent } \\
\text { variable }\end{array}$} \\
\hline & & Process for activities & $\begin{array}{l}\text { QT(includes: QT1, QT2, } \\
\text { QT3, QT4, QT5, QT6, } \\
\text { QT7) }\end{array}$ & \\
\hline TT & $\begin{array}{l}\text { Information } \\
\text { and } \\
\text { communication }\end{array}$ & $\begin{array}{l}\text { Employees understand the company's regulations, } \\
\text { rules, and procedures; The company develops a } \\
\text { clear communication plan; Assigned; Job feedback; } \\
\text { Specific instructions on how to handle when } \\
\text { detecting a mistake; Employees do not feel anxious } \\
\text { about providing information about a mistake; } \\
\text { Communication, business promotion to the outside; } \\
\text { Hotline / inbox for feedback. }\end{array}$ & $\begin{array}{l}\text { TT1; TT2; TT3; TT4; } \\
\text { TT5; TT6; TT7; TT8 }\end{array}$ & $\begin{array}{l}\text { Independent } \\
\text { variable }\end{array}$ \\
\hline GS & Monitoring & $\begin{array}{l}\text { Managers regularly assess their subordinates' } \\
\text { performance; Employees perform the work } \\
\text { properly and adequately according to the issued } \\
\text { process and form; The company performs well on } \\
\text { a periodic review of the processes; The company } \\
\text { ensures independence and objectivity in the } \\
\text { evaluation activities; The person performing the } \\
\text { assessment task has sufficient capacity in the field } \\
\text { of assessment; Evaluation results are useful in } \\
\text { improving policies and processes }\end{array}$ & $\begin{array}{l}\text { GS1; GS2; GS3; GS4; } \\
\text { GS5; GS6 }\end{array}$ & $\begin{array}{l}\text { Independent } \\
\text { variable }\end{array}$ \\
\hline
\end{tabular}


Table 2: Summary of correlation analysis results

\begin{tabular}{|l|l|c|c|c|c|c|c|}
\hline \multicolumn{2}{|c|}{} & HL & MT & RR & HD & GS & TT \\
\hline \multirow{4}{*}{ HL } & Pearson correlation coefficient & 1 & $0.833^{* *}$ & $0.725^{* *}$ & $0.809^{* *}$ & $0.534^{* *}$ & $0.789^{* * *}$ \\
\cline { 2 - 7 } & level Sig. (two-way verification) & & 0.000 & 0.000 & 0.000 & 0.000 & 0.000 \\
\cline { 2 - 8 } & Number of observed samples - N & 250 & 250 & 250 & 250 & 250 & 250 \\
\hline \multirow{4}{*}{ MT } & Pearson correlation coefficient & $0.833^{* *}$ & 1 & $0.664^{* *}$ & $0.829^{* *}$ & $0.453^{* *}$ & $0.775^{* *}$ \\
\cline { 2 - 8 } & Significance level Sig. (two-sided verification) & 0,000 & & 0.000 & 0.000 & 0.000 & 0.000 \\
\cline { 2 - 8 } & Number of observations - N & 250 & 250 & 250 & & & 250 \\
\hline \multirow{4}{*}{ RR } & Pearson product-moment correlation coefficient & $0.725^{* *}$ & $0.664^{* *}$ & 1 & $0.585^{* *}$ & $0.490^{* *}$ & $.640^{* *}$ \\
\cline { 2 - 8 } & The significance Sig. (two-way verification) & 0,000 & 0,000 & & 0.000 & 0.000 & 0.000 \\
\cline { 2 - 8 } & Number of observed samples - N & 250 & 250 & 250 & 250 & 250 & 250 \\
\hline \multirow{4}{*}{ HD } & Pearson correlation coefficient & $0.809^{* *}$ & $0.829^{* *}$ & $0.585^{* *}$ & 1 & $0.447^{* *}$ & $0.739^{* *}$ \\
\cline { 2 - 8 } & level Sig. (two-way verification) & 0.000 & 0.000 & 0.000 & & 0.000 & 0.000 \\
\cline { 2 - 8 } & Number of observations - N & 250 & 250 & 250 & & & 250 \\
\hline \multirow{3}{*}{ NS } & Pearson product-moment correlation coefficient & $0.534^{* *}$ & $0.453^{* *}$ & $0.490^{* *}$ & $0.447^{* *}$ & 1 & $0.420^{* * *}$ \\
\cline { 2 - 8 } & The significance Sig. (two-way verification) & 0.000 & 0.000 & 0.000 & 0.000 & & 0.000 \\
\cline { 2 - 8 } & Number of observed samples - N & 250 & 250 & 250 & 250 & 250 & 250 \\
\hline \multirow{3}{*}{ No. } & Pearson correlation coefficient & $0.789^{* *}$ & $0.775^{* *}$ & $0,640^{* *}$ & $0.739^{* *}$ & $0.420^{* *}$ & 1 \\
\cline { 2 - 8 } & Significance level Sig. (two-way verification) & 0.000 & 0.000 & 0.000 & 0.000 & 0.000 & 250 \\
\cline { 2 - 8 } & Number of observed samples - N & 250 & 250 & 250 & 250 & 250 & 250 \\
\hline
\end{tabular}

Note: $\left({ }^{*}\right),\left({ }^{* *}\right),\left({ }^{* *}\right)$ represent for the significant level at $1 \%, 5 \%$ and $10 \%$, respectively.

Table 3: Summary of regression analysis results

\begin{tabular}{|l|c|c|c|c|c|c|c|}
\hline \multirow{2}{*}{ Model } & \multicolumn{2}{|c|}{ Unstandardized Coefficients } & Standardized Coefficients & \multirow{2}{*}{ Value t } & Sig. & \multicolumn{2}{|c|}{ Collinearity Statistics } \\
& $\mathbf{B}$ & Std. Error & Beta & & & Tolerance & VIF \\
\hline $\mathbf{( 1 )}$ & $\mathbf{( 2 )}$ & $\mathbf{( 3 )}$ & $\mathbf{( 4 )}$ & $\mathbf{( 5 )}$ & $\mathbf{( 6 )}$ & $\mathbf{( 7 )}$ & $\mathbf{( 8 )}$ \\
\hline (Constant) & -0.527 & 0.146 & & -3.617 & 0.000 & & \\
\hline MT & 0.313 & 0.069 & 0.261 & 4.518 & 0.000 & 0.235 & 4.254 \\
\hline RR & 0.269 & 0.052 & 0.209 & 5.176 & 0.000 & 0.484 & 2.066 \\
\hline HD & 0.300 & 0.059 & 0.268 & 5.118 & 0.000 & 0.286 & 3.497 \\
\hline TT & 0.221 & 0.050 & 0.211 & 4.432 & 0.000 & 0.345 & 2.896 \\
\hline GS & 0.123 & 0.039 & 0.105 & 3.168 & 0.002 & 0.719 & 1.390 \\
\hline
\end{tabular}

According to the above table it can be seen that all the values of Sig are 0.000 , satisfying the condition $\operatorname{Sig}<0.05$;

The correlation coefficient $r$ between the dependent variable and the independent variables is equal to 1 , showing that the dependent variable $\mathrm{HL}$ and the independent variables MT, RR, HD, TT, GS have a close linear correlation. Therefore, these independent variables will be included in the regression model to account for the HL dependent variable.

\subsection{Regression Analysis}

The purpose of regression analysis is to estimate the degree of correlation between the dependent variable and the independent variable. Regression analysis results with the help of IBM SPSS Statistics 20 software shown in Table 3

According to the above table, the value of Sig (column 6) of the independent variables are all less than 0.01 , meaning that all 5 independent variables MT, RR, HD, TT, KS are significant in the model with confidence 99. $\%$.

The factors affecting the effectiveness of internal control in transport construction enterprises are shown through the following linear regression equation:

$$
\begin{aligned}
\mathrm{HL}= & -0.527+0.261 \mathrm{MT}+0.209 \mathrm{RR}+0.268 \mathrm{HD}+0.211 \\
& \mathrm{TT}+0.105 \mathrm{GS}
\end{aligned}
$$




\subsection{Regression Model Testing}

Tests performed include:

- Verification of the model's interpretation level (model conformity):

Conformity test of the model: to consider whether the independent variable and the dependent variable exist in a linear relationship with each other or not.

Adjusted R Square coefficient (also known as adjusted R-squared coefficient) is used to test the suitability of the model. This coefficient reflects the influence of the independent variables on the dependent variable. When the $\mathrm{R} 2$ value is 0.5 or higher, the model is evaluated as good.

- Cointegration test of the model (Durbin-Watson)

The d-test is used to test correlation of adjacent errors (first order series correlation). If there is no first order series correlation then the data collected is considered good. The $d$ value of the variable is in the range [0.4]: if the $d$ value approaches 0 , then the error part is positively correlated, progressing to 4 , the error is inversely correlated, if $\mathrm{d}$ is in the range $[1,3]$ then the error parts do not have a first order sequence correlation.

- ANOVA test

The adjusted R-squared coefficient above helps to test the suitability of the model but is limited in the data set of the research sample. We need a test to determine if the regression model is extensible and applicable to the whole population. The condition is a Sig value $<0.05$.

Test the normal distribution of the residual

Identification of a normal distribution: (1) Histograms with normal curve with a symmetrical bell shape with the highest frequencies in the middle and the frequencies lower at the 2 sides; (2) The mean value (mean) is approximately 0 , and the standard deviation (Std.Dve) is approximately equal to 1.

Regression

test results - The results of the R2 and Durbin-Watson tests are shown in Table 4

In this case coefficient Rvalue ${ }^{2}$ of 0.804 calibrated model was rated as good, 5 independent variables included (MT, RR, HD, TT, GS) explained $80.4 \%$ of the variation of the dependent variable (HL), while the remaining 19.6\% was due to the non-model variables and the random error.

- Durbin-Watson value of the model is 1,693 (according to Table 4.17): $1<1,693<3$, so there is no chain correlation in the model

- Model test results are shown in Table 5

According to the above results, we have Sig $=0.000$ $<0.005$, so the regression model was built in accordance with the whole.

- Test the normal distribution of the residual

Table 4: Results of testing the $\mathrm{R}^{2}$ and Durbin-Watson

\begin{tabular}{|l|c|c|c|c|c|}
\hline Model & Coefficient R & R Square & adjusted R Square & Std. Error & Durbin-Watson value \\
\hline 1 & $0.899^{a}$ & 0.808 & 0.804 & 0.29843 & 1.693 \\
\hline
\end{tabular}

Table 5: Test results ANOVA

\begin{tabular}{|l|l|c|c|c|c|c|}
\hline \multicolumn{2}{|l|}{ Model } & Sum of Squares & freedom - df & Mean Square & F value & level Sig. \\
\hline \multirow{4}{*}{1} & Regression & 91.689 & 5 & 18.338 & 205.903 & $.000^{\mathrm{b}}$ \\
\cline { 2 - 7 } & Residual & 21.731 & 244 & .089 & & \\
\cline { 2 - 7 } & Total & 113.420 & 249 & & & \\
\hline
\end{tabular}

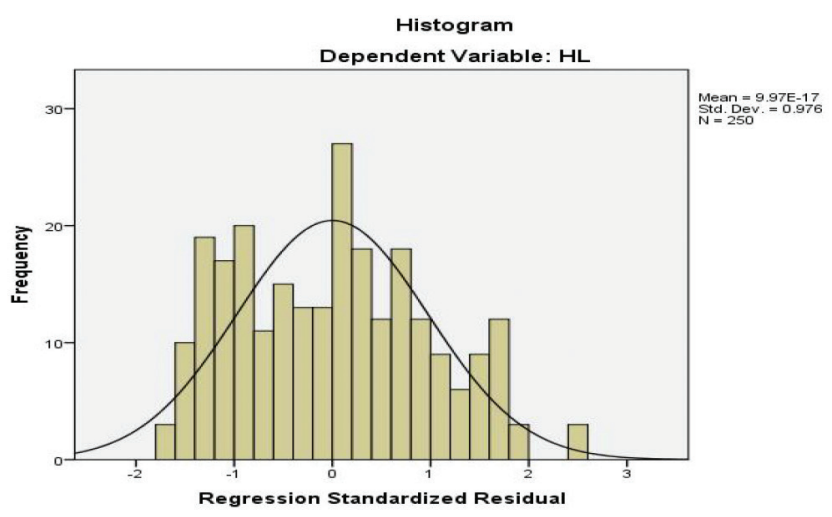

Figure 1: Scatterof the normalized residue 
We see the model satisfying the condition of the residue, plot- Histograms with normal curve with opposite bell shape deserve.

- The remainder has approximately standard distribution (Mean value $=9.97 \mathrm{E}-17$ is approximately equal to 0 , standard deviation Std.Dev. $=0.976$ is approximately equal to 1 )

Thus, a linear regression model is built. The above construction does not violate the assumptions required in linear regression.

\section{Conclusions and Recommendations}

\subsection{Recommendations}

According to research results, it can be seen that control activities have a great influence on the effectiveness of internal controls in transport construction enterprises in Vietnam. In order to increase the effectiveness of the internal control of a Vietnamese transport construction enterprises, enterprises need to improve their work processes. Specifically, a workflow should ensure: (1) the steps to perform the work and (2) what risks and controls at each step. Firstly, enterprises should use tools such as flowcharts, and raci matrices to show the sequence of work steps and clarify who is doing it, who is ultimately responsible, who is questioned. opinion, who is informed for each content, and scope or category. Second, enterprises need to focus on risk assessment, thereby building control points in work processes to prevent, detect and correct risks.

\subsection{Conclusion}

The main objective of this study is to determine the influence of internal control components (control environments, risk assessments, control activities, communications, surveillance) to effect internal control. The results of the analysis and testing on the data collected from the research samples show that all internal control components affect the effectiveness of internal control and explain $80.4 \%$ of the variation of the internal control effect of the Vietnamese transport construction enterprise. All five components positively affect the effectiveness of internal controls in the order of influence, which are control activities, control environment, communication, risk assessment and monitoring.

\section{References}

Amudo, A., \& Inanga, E. L. (2009). Evaluation of internal control systems: A case study from Uganda. International Research Journal of Finance and Economics, 27(1), 124-144.

Ayagre, P., Appiah-Gyamerah, I., \& Nartey, J. (2014). The effectiveness of Internal Control Systems of banks: The case of Ghanaian banks. International Journal of Accounting and Financial Reporting, 4(2), 377. Doi:10.5296/ ijafr.v4i2.6432.
COSO. (2013). Internal Control - Integrated Framework Executive Summary. https://www.COSO.org/Documents/990025PExecutive-Summary-final-may20.pdf (pdf).

Dang, H. T., Phan, D. T., \& Nguyen, H. T. (2020). Factors Affecting Financial Risk: Evidence from Listed Enterprises in Vietnam. Journal of Asian Finance, Economics and Business, 7(9), 11-18. https://doi.org/10.13106/jafeb.2020.vol7.no9.011.

Mayo, G. E. (2004). The Human Problems of an Industrial Civilization. New York, NY: Routledge.

Freeman, R. E. (2010). Strategic management. Cambridge, UK: Cambridge University Press.

Gamage, C. T., Lock, K. L., \& Fernando, A. A. J. (2014). A proposed research framework: Effectiveness of internal control system in state commercial banks in Sri Lanka. International Journal of Scientific Research and Innovative Technology, 1(5), 25-44.

Hardiningsih, P., Udin, U., Masdjojo, G. N., \& Srimindarti, C. (2020). Does Competency, Commitment, and Internal Control Influence Accountability?. Journal of Asian Finance, Economics, and Business, 7(4), 223-233. https://doi. org/10.13106/jafeb.2020.vol7.no4.223

Hellriegel, D., Slocum, J. W., \& Woodman, R. W. (1986). Organizational behavior. St. Paul: West Publishing Co.

$\mathrm{Vu}, \mathrm{H} . \mathrm{T}$. (2016). Factors affecting the effectiveness of the internal control system in Vietnamese commercial banks. $\mathrm{PhD}$ thesis, University of Economics, Ho Chi Minh City.

Jensen, M. C., \& Meckling, W. H. (1976). Theory of the firm: Managerial behavior, agency costs and ownership structure. Journal of Financial Economics, 3(4), 305-360. https://doi. org/10.1016/0304-405X(76)90026-X

Kiel, L. D., \& Elliott, E. W. (1997). Chaos Theory in the Social Sciences. Perseus Publishing. https://upcommons.upc.edu/ handle/2117/81242

Luft, J., \& Shields, M. D. (2003). Mapping management accounting: Graphics and guidelines for theory-consistent empirical research. Accounting, Organizations and Society, 28(2-3), 169249. https://doi.org/10.1016/S0361-3682(02)00026-0.

Nguyen, T. X. H., Pham, T. H., Dao, T. N., Nguyen, T. N., \& Tran, T. K. N. (2020). The Impact of Foreign Ownership and Management on Firm Performance in Vietnam. Journal of Asian Finance, Economics and Business, 7(9), 409-418. https:// doi.org/10.13106/jafeb.2020.vo17.no9.409

Otley,D.T.(1980).Thecontingencytheoryofmanagementaccounting: achievement and prognosis. In: Readings in accounting for management control (pp. 83-106). Boston, MA: Springer. https:// link.springer.com/chapter/10.1007/978-1-4899-7138-8_5

Ferreira, A., \& Otley, D. (2009). The design and use of performance management systems: An extended framework for analysis. Management Accounting Research, 20(4), 263-282. https://doi. org/10.1016/j.mar.2009.07.003

Sultana, R., \& Haque, M. E. (2011). Evaluation of Internal Control Structure: Evidence from Six Listed Banks in Bangladesh. ASA University Review, 5(1), 69-81. http://www.asaub.edu.bd/data/ asaubreview/v5n1s14.pdf 